\title{
Análise ultraestrutural do colágeno de feridas cutâneas de coelhos tratadas com plasma rico em plaquetas de equino
}

\author{
[Ultrastructural analysis of the collagen of rabbit skin wounds treated with \\ platelet-rich equine plasma] \\ R.S. Rezende ${ }^{1}$, D. Eurides $^{2}$, E.G.L. Alves ${ }^{1}$, G.C. Venturini ${ }^{1}$, R.N. Alves $^{2}$, R.L. Felipe ${ }^{3}$ \\ ${ }^{1}$ Universidade de Uberaba - Uberaba, MG \\ ${ }^{2}$ Universidade Federal de Uberlândia - Uberlândia, MG \\ ${ }^{3}$ Aluno de pós-graduação - Universidade Federal de Uberlândia - Uberlândia, MG
}

\begin{abstract}
RESUMO
O colágeno é sintetizado e segregado no espaço extracelular e organizados em fibrilas estriadas de acordo com o tipo de tecido. Utilizaram-se 24 coelhos brancos da raça Nova Zelândia, com idade de 12 meses e com 3,0kg de peso corporal, para avaliar a porcentagem de colágeno das feridas cutâneas tratadas com plasma rico em plaquetas de equino e pomada contendo gentamicina, sulfanilamida, sulfadiazina, ureia e vitamina A. Os animais foram separados em quatro grupos de igual número e submetidos à remoção de pele na região das linhas médias dorsal torácica (feridas tratadas) e lombar (feridas controle). As feridas torácicas foram tratadas com plasma rico em plaqueta de equino e pomada contendo gentamicina, sulfanilamida, sulfadiazina, ureia e vitamina A, e as do grupo controle somente com a pomada. Dos animais do grupo I, foi coletado tecido cutâneo, para a avaliação histológica e a ultraestrutural, com três dias de pós-operatório; dos animais do grupo II, com sete dias; do grupo III, com 14 dias; e do grupo IV, com 21 dias. Decorrido o período de avaliação de cada grupo, foi coletado fragmento de pele para avaliação da porcentagem de colágeno, bem como do diâmetro e da densidade da fibrila de colágeno por microscopia eletrônica de transmissão. O tratamento com PRP de equino associado à aplicação tópica da pomada mostrou-se eficaz na maturação das fibrilas colágenas e na antecipação do processo cicatricial.
\end{abstract}

Palavras-chave: fibrila, colágeno, picrosírius, transmissão

\begin{abstract}
Collagen is synthesized and secreted into the extracellular space and organized into striated fibrils according to the tissue type. This study evaluated the concentration of collagen in rabbit skin wounds treated with equine platelet-rich plasma (PRP) and ointment containing gentamicin, sulfanilamide, sulfadiazine, urea, and vitamin A. Twenty-four New Zealand white rabbits aged 2 to 12 months and weighing $3.0 \mathrm{~kg}$ were included. The animals were allocated equally into four groups and the skin was removed from the thoracic dorsal midline (treated wound) and lumbar (control wound) regions. The thoracic wounds were treated with equine PRP and ointment containing gentamicin, sulfanilamide, sulfadiazine, urea, and vitamin $A$, and the control group was treated with the ointment alone. For histological and ultrastructural assessment, cutaneous tissue was collected on postoperative days 3 (group I), 7 (group II), 14 (group III), and 21 (group IV). After the evaluation period, in each group, a skin fragment was collected for analysis of the collagen concentration, as well as the collagen fibril diameter and density by transmission electron microscopy. The results indicated that treatment with equine PRP combined with topical application of the ointment was effective in facilitating the maturation of collagen fibrils and the wound healing process.
\end{abstract}

Keywords: fibrils, collagen, picrosirius, transmission

Recebido em 7 de setembro de 2018

Aceito em 17 de outubro de 2019

E-mail: rezendehvu@hotmail.com 


\section{INTRODUÇÃO}

A cicatrização é um processo que restaura a integridade física externa das estruturas corporais e envolve integrações complexas entre células e vários outros fatores (Masi et al., 2016). É um processo dinâmico e complexo, composto pelas fases de inflamação do tecido, proliferação e remodelação (Masi et al., 2016). O processo de cicatrização compreende a matriz extracelular, citocinas, células sanguíneas e fatores de crescimento (Campos et al., 2007; Abegão et al., 2015; Masil et al., 2016).

Fatores de crescimento são proteínas que estimulam e ativam a proliferação celular por ativação da angiogênese, mielogênese e genetranscrição, entre outras reações, que ativam e aceleram o processo de cicatrização (Masi et al., 2016). Entre os fatores de crescimento plaquetário, os mais importantes para a cicatrização de feridas incluem o fator de crescimento epitelial (EGF), o de crescimento derivado de plaquetas (PDGF), o de crescimento transformador beta (TGF-b) e o de crescimento endotelial vascular (VEGF) (Ma e Bazan, 2000).

As moléculas de colágeno são polimerizadas e segregadas no espaço extracelular e organizadas em fibrilas estriadas com uma organização específica para cada tipo de tecido (Birk et al., 1990). Os tipos de colágeno podem ser importantes na determinação da arquitetura de fibrilas. Nos estudos de remontagem, o colágeno in vitro tipo I forma fibrilas mais espessas do que o colágeno tipo III, enquanto as fibrilas de colágeno tipo II geralmente apresentam os diâmetros menores (Birk et al., 1990; Tonniges et al., 2016). As fibras transmitem forças, dissipam energia e evitam falhas mecânicas prematuras em tecidos normais. Além disso, fornecem sugestões biológicas para células adjacentes que regulam uma variedade de respostas funcionais (Huang et al., 2001).

Diferentes tipos de colágeno demonstraram formar fibrilas heterotípicas em uma variedade de tecidos, assim como os tipos de colágeno I e V no estroma corneano secundário, os tipos I e II no estroma corneano primário, os tipos II, IX e XI em cartilagem e os tipos I e III em derme e tendão (Birk et al., 1990; Houdek et al., 2016).
As fibrilas variam, em diâmetro, de 12 a 500nm em função do tecido e da idade, e são o elemento de tensão primário dos tecidos, como tendões, ligamentos, pele, cartilagem, osso, fáscia, cápsulas articulares, vasos sanguíneos e outros órgãos ocos. Muito se sabe sobre a estrutura dos genes de colágeno fibrilar, entretanto questões fundamentais permanecem sem resposta sobre a montagem e a organização das fibrilas (Starborg et al., 2013).

A microscopia eletrônica de transmissão (MET) é importante para avaliar fibrilas de colágeno em que o diâmetro é o parâmetro mais comumente medido. No entanto, as funções das células e dos tecidos dependem não apenas das distribuições do diâmetro da fibrila do colágeno mas também do número, da porcentagem, da fração do volume (FVF) e do comprimento das fibras (Birk et al., 1990; Starborg et al., 2013).

Objetivou-se com o presente trabalho avaliar a ultraestrutura e a concentração do colágeno das feridas cutâneas de coelhos tratadas e não tratadas com plasma rico em plaquetas heterólogo de equino.

\section{MATERIAL E MÉTODOS}

O experimento foi aprovado pelo Comitê de Ética em Experimentação Animal da Universidade de Uberaba, ofício Ceea $\mathrm{n}^{\mathrm{o}}$ 034/2016, para utilização de 24 coelhos brancos da raça Nova Zelândia, machos hígidos, com idade média de 12 meses e com aproximadamente $3,0 \mathrm{~kg}$ de peso corporal. Os animais foram separados em quatro grupos de igual número $(n=6)$ e considerados hígidos após terem sido submetidos a avaliações clínicas e exames laboratoriais de hemograma e coproparasitológico direto.

Os coelhos foram submetidos à remoção de pele na região das linhas médias dorsal torácica e lombar, sendo a torácica considerada a ferida tratada (FT) e a lombar, a ferida controle (FC). As torácicas foram tratadas com plasma rico em plaquetas de equino e pomada contendo gentamicina, sulfanilamida, sulfadiazina, ureia e vitamina A. As lombares foram tratadas com a mesma pomada. Dos animais do grupo I, foi coletado tecido cutâneo para a avaliação histológica, com três dias de pós-operatório (PO); dos animais do grupo II, com sete dias; do 
grupo III, com 14 dias; e os do grupo IV, com 21 dias de PO. Os coelhos foram mantidos em gaiolas individuais com ração, feno e água potável à vontade.

Para a produção do plasma rico em plaquetas, foi utilizado um equino macho, da raça Quarto de Milha, com $550 \mathrm{~kg}$ de peso corporal e com idade aproximada de 12 anos. $\mathrm{O}$ equino foi considerado saudável após avaliações clínicas, exame laboratorial de hemograma e contagem de ovos por grama de fezes (OPG), permanecendo alojado em piquete com gramínea de tifton 85 (Cynodon spp.), com água potável e suplementação mineral à vontade.

Diariamente, foram obtidos $40 \mathrm{~mL}$ de sangue da veia jugular externa de um equino. $\mathrm{O}$ sangue foi distribuído em tubos de $4,0 \mathrm{~mL}$ contendo citrato de sódio a 3,2\%. O material foi centrifugado, em centrífuga Celm, série 4161, durante 20 minutos, a 2.220rpm (400G), para a separação celular por meio de gradiente de concentração. Foi pipetada a fração de plasma e plaquetas contida na parte superior do tubo, a qual foi armazenada em recipiente sem anticoagulante. A porção retirada foi novamente centrifugada durante 10 minutos, a 2.220rpm (400G). Dois terços do componente superior do soro foram removidos por se tratar do plasma pobre em plaquetas, e um terço restante, no fundo do frasco, foi considerado o plasma rico em plaquetas. Antes da ativação do PRP com cloreto de cálcio a 5\%, o plasma foi avaliado, para se verificar a viabilidade plaquetária e a contagem total de células. A contagem manual das plaquetas foi efetuada em câmara de Neubauer e, para ser ativado e considerado PRP, a contagem foi superior a quatro vezes a contagem plaquetária inicial, portanto, para cada $0,5 \mathrm{~mL}$ do PRP, foi adicionado $0,25 \mathrm{~mL}$ de cloreto de cálcio a $5 \%$. A solução foi homogeneizada e mantida em repouso, em caixa térmica com gelo, por aproximadamente 10 minutos, para transporte até o local onde os curativos foram realizados (Eurides et al., 2015).

Os animais foram submetidos a jejum hídrico e de alimentos sólidos por seis horas. Foram, então, anestesiados com cetamina $(35 \mathrm{mg} / \mathrm{kg}, \mathrm{IM})$ e xilazina $(5,0 \mathrm{mg} / \mathrm{kg}, \quad \mathrm{IM})$ e submetidos à tricotomia da linha média dorsal torácica ao longo das regiões interescapular e ilíaca. Após antissepsia tópica do campo cirúrgico com clorexidina degermante $2 \%$ e clorexidina alcoólica $0,5 \%$, foram realizadas, na linha média dorsal torácica, duas incisões de pele em formato circular, com um molde circular de metal com $3,0 \mathrm{~cm}$ de diâmetro, equidistantes uma da outra em aproximadamente $10,0 \mathrm{~cm}$, formando-se as feridas torácica (tratada) e lombar (controle). Para controle da dor, os coelhos foram medicados com tramadol $(0,5 \mathrm{mg} / \mathrm{kg}$, IM), duas vezes ao dia, durante três dias.

Os coelhos foram mantidos em gaiolas individuais. $\mathrm{O}$ primeiro curativo foi realizado às oito horas, sendo ambas as feridas irrigadas com solução salina a $0,9 \%$ e posteriormente higienizadas com gaze. Em seguida, foi aplicado, nas feridas tratadas, $0,2 \mathrm{~mL}$ de concentrado de plasma rico em plaquetas de equino, em concentração média de 1.578 .750 plaquetas $/ \mathrm{mm}^{3}$ ( \pm 202.723 ), produzidas no mesmo dia e ativadas com cloreto de cálcio a $5 \%$ no momento do procedimento. Nas feridas controle, foi aplicado $1,5 \mathrm{~g}$ de uma pomada contendo gentamicina, sulfanilamida, sulfadiazina, ureia e vitamina A (Vetaglós, Vetnil, Brasil). O segundo curativo foi realizado às 20 horas, aplicado em ambas as feridas, após irrigadas com solução de cloreto de sódio a $0,9 \%, 1,5 \mathrm{~g}$ de Vetaglós.

Decorridos os períodos de observação dos grupos, os coelhos foram eutanasiados para remoção de cerca de $3,0 \mathrm{~cm}$ das bordas e do leito das feridas. As amostras foram fixadas, durante 48 horas, em formol $10 \%$, desidratadas em solução de concentrações crescentes de etanol e incluídas em parafina. O material foi seccionado em micrótomo Leika, modelo 2145, com 6,0 $\mu \mathrm{m}$ de espessura, para serem confeccionadas as lâminas histológicas. Os cortes foram corados pelo picrosírius red, montados entre lâmina e lamínula com resina sintética e avaliados em microscopia óptica (microscópio Nikon eclipse, modelo E200). Após fotografadas, as imagens foram analisadas pelo programa ImageJ para se calcular a área e a porcentagem de colágeno presente em cada ferida.

Para a avaliação em microscopia eletrônica de transmissão Hitachi High-Tech, modelo HT7700, com aumento de 40.000 vezes, as amostras foram fixadas em solução de glutaraldeído 2,5\%, durante 24 horas. Em seguida, foram acondicionadas em recipiente de vidro contendo solução tampão de PBS com pH de 7,2 a 7,4, 
tampadas e refrigeradas em geladeira a seis graus. Foram coletadas cinco amostras de cada ferida, e a solução de PBS foi trocada, a cada sete dias, até o processamento. $\mathrm{O}$ material foi pós-fixado em solução de tetróxido de ósmio a $2 \%$, por uma hora. Adicionou-se ferrocianeto de potássio $1,25 \%$ à solução, durante 30 minutos. As amostras foram desidratadas em séries crescentes de álcool a 50\%, 70\%, 80\%, 90\%, $95 \%, 100 \%, 100 \%$ e $100 \%$, permanecendo cinco minutos nos cinco primeiros banhos e 10 minutos nos três últimos. Em seguida, as amostras foram mantidas em óxido de propileno a $100 \%$, por 10 minutos, sendo o processo repetido por três vezes. Posteriormente, o material foi colocado em solução de óxido de propileno e resina Epon 2:1, por 12 horas. Após esse período, a solução foi substituída por outra de proporção de $1: 1$, sendo uma parte de óxido de propileno e outra de resina Epon, por mais 12 horas. Decorridas as 12 horas, os frascos foram colocados na estufa a $37^{\circ} \mathrm{C}$, por 12 a 24 horas. Depois da evaporação de todo óxido de propileno, os blocos foram embebidos em resina pura e mantidos, durante duas horas, em estufa a $37^{\circ} \mathrm{C}$. Após esse período, as amostras foram acondicionadas em formas com resina Epon, identificadas e mantidas em estufa, a $60^{\circ} \mathrm{C}$ por dois dias. Posteriormente, obtiveram-se cortes ultrafinos no ultramicrótomo, que foram contrastados com acetato de uranila e citrato de chumbo (Bozzola e Russell, 2006).

Após contrastados e para a obtenção dos valores médios do diâmetro $(\mathrm{nm})$ e da densidade das fibrilas de colágeno por $\mu \mathrm{m}^{2}$, foram fotografados 100 campos microscópicos em aumento de 40.000 vezes e em escala de $500 \mathrm{~nm}$, sendo as imagens analisadas pelo programa ImageJ.
Para a comparação entre os grupos (GI, GII, GIII e GIV) em relação à porcentagem de colágeno, ao diâmetro da fibrila de colágeno e à densidade de fibrila de colágeno por $\mu \mathrm{m}^{2}$, utilizou-se o teste de Tukey, sendo consideradas significativas as diferenças das médias entre os grupos para os valores de "P" iguais ou inferiores a 0,05. Também foi realizada análise de correlação linear entre essas variáveis, nas feridas controle e tratadas nos diferentes grupos de observação, considerando nível de significância de 5\%. Para todas as análises, foi utilizado o programa estatístico R.

\section{RESULTADOS E DISCUSSÃO}

Observou-se precocidade na reepitelização das bordas das feridas tratadas com plasma rico em plaquetas de equino associado à aplicação tópica da pomada contendo gentamicina, em relação às não tratadas com o plasma (Fig. 3,5 e 7). Entretanto, não ocorreu diferença significativa entre as feridas $(\mathrm{P}>0,05)$, quanto à porcentagem de colágeno, nos diferentes grupos de observação (Tab. 1). Em experimento semelhante, a porcentagem de colágeno se mostrou significativamente maior nas feridas tratadas com PRP, no terceiro dia após a lesão, em relação às feridas do grupo controle (De Souza et al., 2014; Mori et al., 2014; De Sousa et al., 2015). As divergências dos resultados podem ser justificadas pelas diferenças de metodologias, como as espécies de animais avaliadas, e a coloração picrosírius empregada, uma vez que esses fatores podem alterar a sensibilidade da leitura do programa ImageJ para a avaliação da porcentagem de colágeno.

Tabela 1. Média da porcentagem, diâmetro e densidade da fibrila de colágeno das feridas cutâneas de coelhos, controle e tratada com PRP e pomada de gentamicina, nos diferentes grupos de observação.

\begin{tabular}{|c|c|c|c|c|c|c|c|c|}
\hline \multirow{2}{*}{ Características } & \multicolumn{2}{|c|}{ GI (3 dias) } & \multicolumn{2}{|c|}{ GII (7 dias) } & \multicolumn{2}{|c|}{ GIII (14 dias) } & \multicolumn{2}{|c|}{ GIV (21 dias) } \\
\hline & $\mathrm{FC}$ & FT & $\mathrm{FC}$ & FT & $\mathrm{FC}$ & FT & $\mathrm{FC}$ & FT \\
\hline Colágeno & 41,50 & $47,41 \mathrm{~A}$ & $46,99 \mathrm{~A}$ & $47,76 \mathrm{~A}$ & 44,30 & $43,79 \mathrm{~A}$ & 34,42 & $38,64 \mathrm{~A}$ \\
\hline Diâmetro & A & $129,95 \mathrm{AB}$ & $104,98 \mathrm{BC}$ & $138,23 \mathrm{~A}$ & A & $97,99 \mathrm{C}$ & A & $97,24 \mathrm{C}$ \\
\hline \multirow[t]{4}{*}{ Densidade } & 95,33 & $75,00 \mathrm{AB}$ & $29,00 \mathrm{BC}$ & $75,00 \mathrm{~A}$ & 31,40 & $109,00 \mathrm{C}$ & 43,95 & $117,00 \mathrm{C}$ \\
\hline & & & & & $\mathrm{D}$ & & $\mathrm{D}$ & \\
\hline & 34,00 & & & & 45,00 & & 60,00 & \\
\hline & $\mathrm{C}$ & & & & $\mathrm{D}$ & & $\mathrm{D}$ & \\
\hline
\end{tabular}

FC: ferida controle, FT: ferida tratada. Médias das características colágeno (\%), diâmetro (nm) e densidade $\left(\right.$ fibrilas/ $\left.\mu \mathrm{m}^{2}\right)$ seguidas por letras diferentes diferem pelo teste de Tukey $(\mathrm{P}<0,05)$. 
A fim de analisar a regeneração da derme das feridas, utilizou-se a microscopia eletrônica de transmissão para revelar os padrões de formação do colágeno, o diâmetro individual da fibrila de colágeno e a densidade das fibrilas no local da ferida. Notou-se que o diâmetro e a densidade da fibrila de colágeno foram diferentes entre as feridas tratadas e controle em todos os grupos de observação (Fig. 2, 4, 6 e 8). Também foi verificado o predomínio de maior diâmetro e de maior densidade de fibrila para as feridas tratadas com PRP heterólogo associado à pomada em relação às feridas controle $(\mathrm{P}<0,05)$ (Tab. 1). O mesmo padrão foi observado em camundongos por Mori et al. (2014), os quais referiram que as diferenças de montagem de densidade de colágeno entre as feridas tratadas e controle desempenham importante função na reepitelização na fase de maturação das feridas.
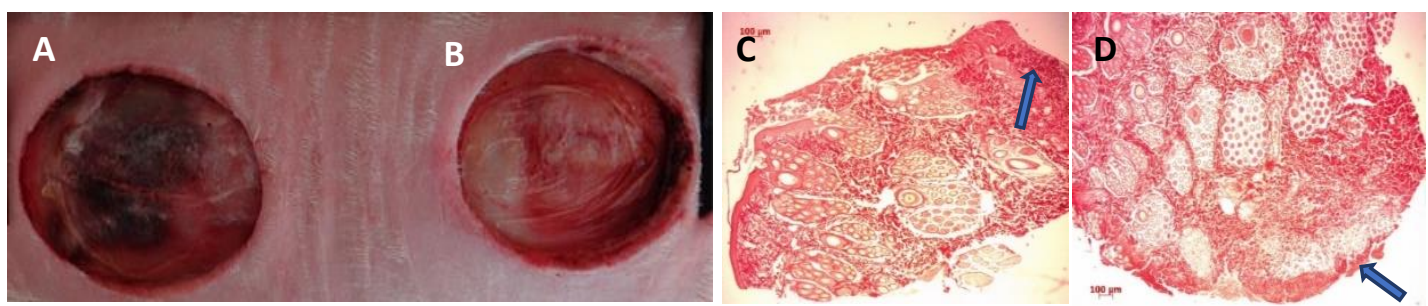

Figura 1. Feridas cutâneas de coelhos do grupo I decorridos três dias de pós-operatório. Observar a semelhança macroscópica entre a ferida tratada (A) e a controle (B), a fotomicrografia do grupo I decorridos três dias de pós-operatório, com presença de crosta e semelhança na quantidade de colágeno na ferida tratada (C), (seta), e na controle (D), (seta), (coloração picrosírius, aumento de cinco vezes e escala de $100 \mu \mathrm{m})$.
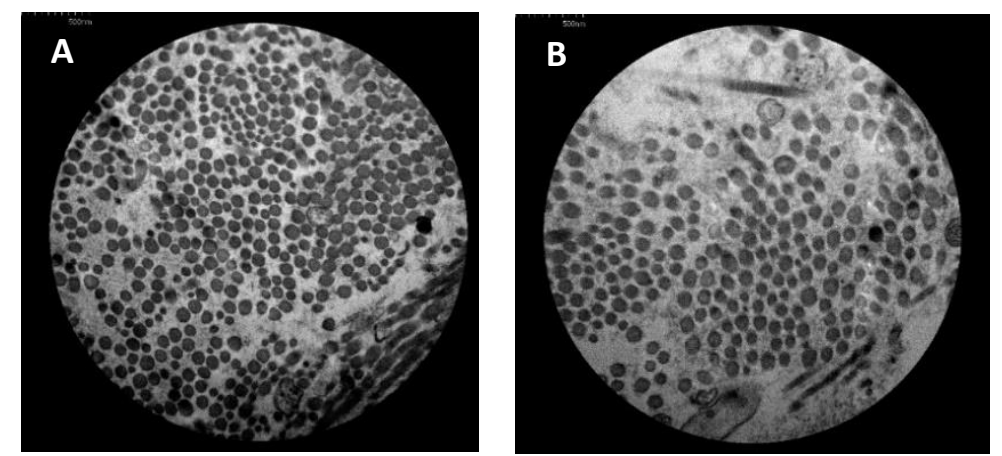

Figura 2. Eletromicrografia do grupo I decorridos três dias de pós-operatório. Verificar o maior diâmetro e a maior densidade por campo das fibrilas colágenas na ferida tratada $(\mathrm{A})$ em relação à controle (B), (aumento de 40.000 vezes).
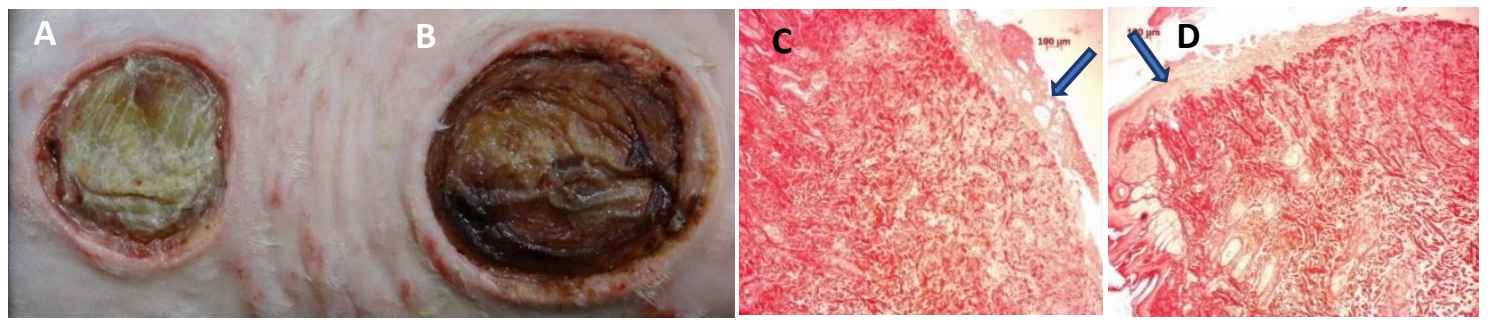

Figura 3. Feridas cutâneas de coelhos do grupo II decorridos sete dias de pós-operatório. Observar a redução de área da ferida tratada (A) em comparação com a controle (B), a fotomicrografia do grupo II decorridos sete dias de pós-operatório, com presença de crosta e semelhança na quantidade de colágeno na ferida tratada (C), (seta), e controle (D), (seta), (coloração picrosírius, aumento de cinco vezes e escala de $100 \mu \mathrm{m})$. 

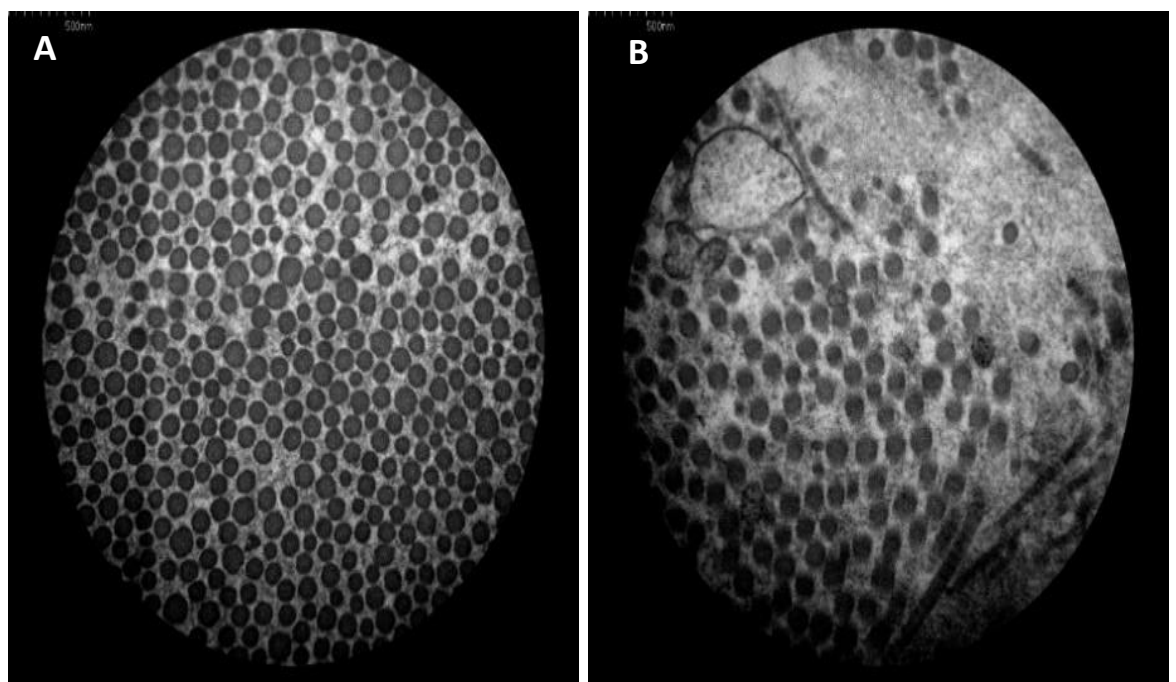

Figura 4. Eletromicrografia do grupo II decorridos sete dias de pós-operatório. Observar o maior diâmetro e a maior densidade por campo das fibrilas colágenas na ferida tratada $(\mathrm{A})$ em relação à controle (B), (aumento de 40.000 vezes).

As fibrilas de colágeno em feridas recentes são de 12 a 50nm de diâmetro e embaladas de forma muito curta em feixes curvilíneos, portanto, não são prontamente detectáveis por microscopia óptica. As fibras em feridas antigas podem apresentar um diâmetro de até 500nm, mas se encontram no limite da resolução da maioria dos microscópios de luz (Starborg et al., 2013; Andrade et al., 2016). Essa observação não é coincidente com o verificado neste experimento, uma vez que foi notado um diâmetro maior nas feridas com três e sete dias de pós-operatório (Fig. 2 e 4) do que nas feridas com 14 e 21 dias de indução (Fig. 6 e 8), tendo as tratadas com PRP apresentado um diâmetro de fibrilas de colágeno significativamente maior do que as controle, assim como a densidade de fibrila colágena por $\mu \mathrm{m}^{2}(\mathrm{P}<0,05)$, (Tab. 1). Apesar de a avaliação da porcentagem de colágeno, nos cortes histológicos corados com picrosírius, não ter revelado diferenças entre as feridas nos diferentes grupos (Fig. 1, 3, 5 e 7), a microscopia eletrônica mostrou-se sensível na diferença de maturação entre as fibrilas de colágeno, tanto nas feridas controle como nas tratadas.
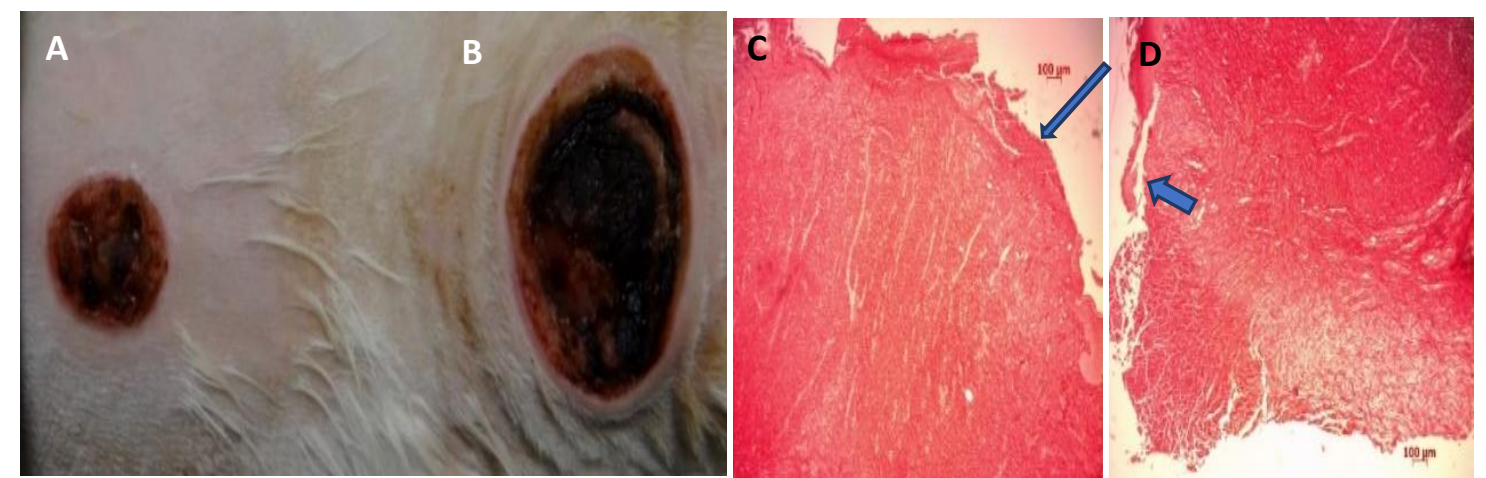

Figura 5. Feridas cutâneas de coelhos do grupo III decorridos 14 dias de pós-operatório. Observar a redução de área da ferida tratada (A) em comparação com a controle (B), a fotomicrografia do grupo III decorridos 14 dias de pós-operatório, com diminuição da crosta e semelhança na quantidade de colágeno na ferida tratada (C), (seta), e na controle (D), (seta), (coloração picrosirius, aumento de cinco vezes e escala de $100 \mu \mathrm{m})$. 

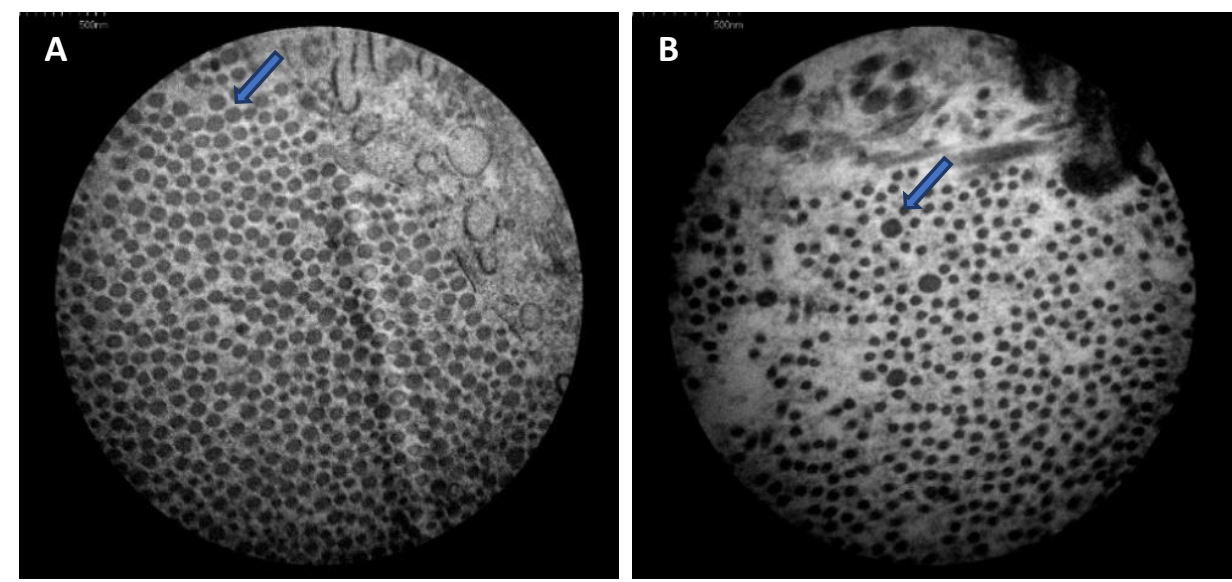

Figura 6. Eletromicrografia do grupo III decorridos 14 dias de pós-operatório. Notar o maior diâmetro e a maior densidade por campo das fibrilas colágenas na ferida tratada $(\mathrm{A})$ em relação à controle $(\mathrm{B})$. Em ambas as feridas, são notadas fibrilas de elastina, (setas), (aumento de 40.000 vezes).
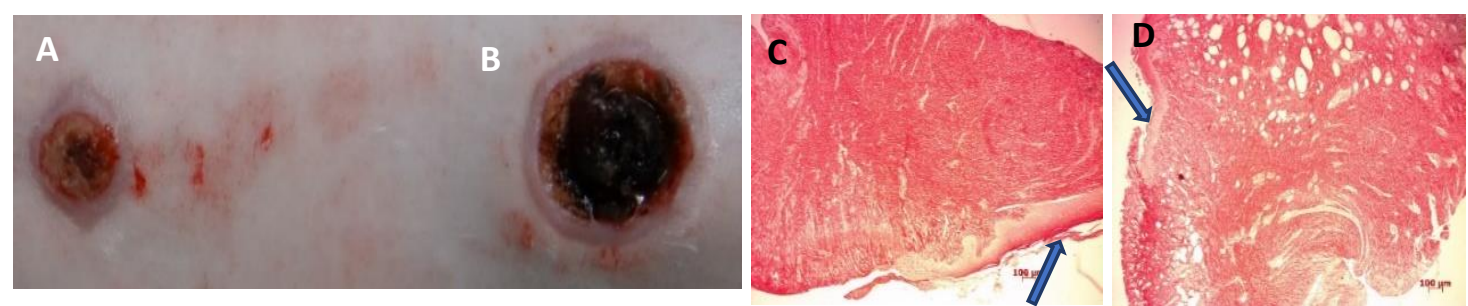

Figura 7. Feridas cutâneas de coelhos do grupo IV decorridos 21 dias de pós-operatório. Observar a redução de área da ferida tratada (A) em comparação com a controle (B), a fotomicrografia do grupo IV decorridos 21 dias de pós-operatório, com a reepitelização e a maior quantidade de colágeno na ferida tratada (C), (seta), em comparação com a controle (D), (seta), (coloração picrosírius, aumento de cinco vezes e escala de $100 \mu \mathrm{m})$.
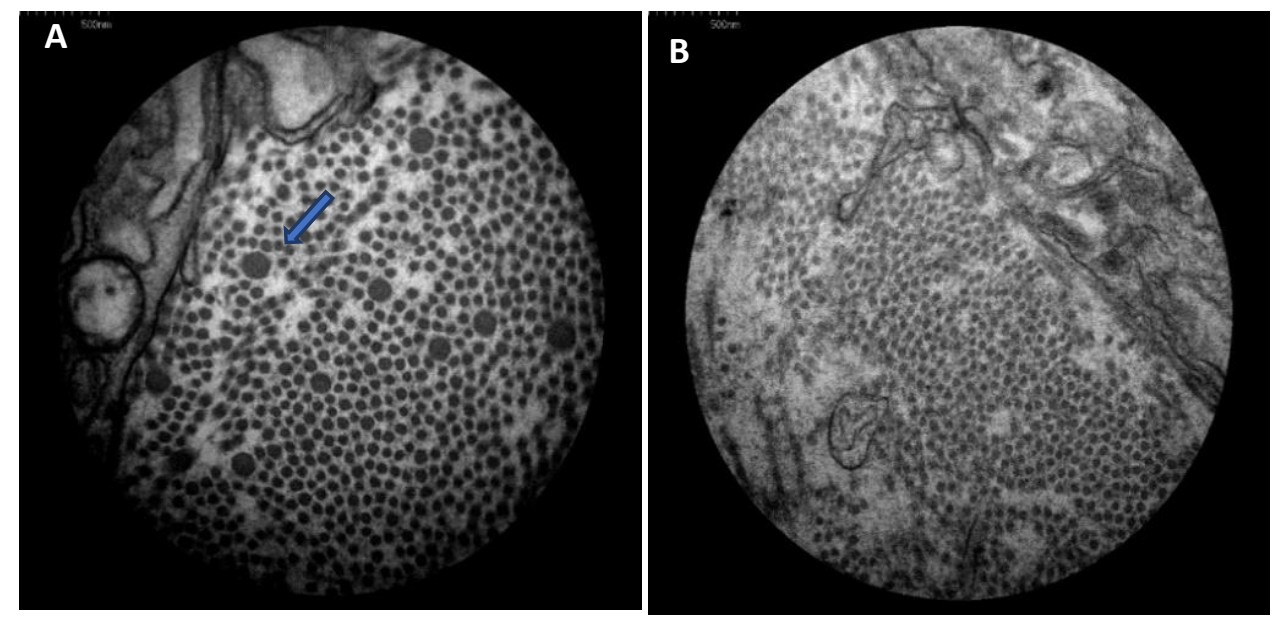

Figura 8. Eletromicrografia do grupo IV decorridos 21 dias de pós-operatório. Constatar o maior diâmetro e a maior densidade por campo das fibrilas colágenas na ferida tratada (A) em relação à controle (B). Presença de fibrilas de elastina na ferida tratada (A), (seta), (aumento de 40.000 vezes).

Foi observada, em ambas as feridas, uma correlação linear negativa significativa $(\mathrm{P}<0,05)$ entre o diâmetro $(\mathrm{nm})$ e a densidade da fibrila por $\mu \mathrm{m}^{2}(\mathrm{r}=-0,14)$ e uma correlação negativa significativa $(\mathrm{P}<0,01)$ entre o diâmetro da fibrila e a porcentagem de colágeno $(r=-0,16)$, as quais 
foram observadas nas avaliações histológicas realizadas por meio da coloração picrosirius. Notou-se que, quanto maior o diâmetro da fibrila de colágeno, menor é a sua densidade por $\mu \mathrm{m}^{2} \mathrm{e}$, portanto, menor a sua porcentagem no tecido lesado. No entanto, não foi percebida, pela coloração picrosírius, diferença significativa na porcentagem de colágeno nas feridas durante os tratamentos $(\mathrm{P}>0,05)$, uma vez que a avaliação histológica se demonstrou pouco sensível. Tal característica é verificada com maior frequência nas feridas com três e sete dias pós-indução, ou seja, no grupo I e no grupo II, respectivamente. Durante a fibroneogênese, pode existir a interação de dois ou mais tipos de colágeno dentro de uma fibrila ou a sua interação com a matriz interfibrilar, determinando, assim, o seu diâmetro (Birk et al., 1990; Aleixo et al., 2011; Hermeto et al., 2012; Minamimura et al., 2014). Em experimentos realizados com tecido corneano, tratados com plasma rico em plaquetas, observou-se ampla gama de diâmetros, os quais diminuíram progressivamente ao longo do período após a indução $(10 \%, 144 \pm 39 \mathrm{~nm}, 20 \%, 101 \pm 30 \mathrm{~nm}$, 30\%, $85 \pm 21 \mathrm{~nm}$ ), (Birk et al., 1990; Arora et al., 2016; Chang et al., 2017).

Apesar das características distintas entre os tipos de colágeno I, presente na córnea, e de colágeno III, na pele, verificou-se o padrão semelhante ao observado neste estudo, em que o diâmetro da fibrila colágena diminui à medida que o período decorrido pós-lesão progride. Isso demonstra desiguais graus de maturidade da fibrila de colágeno nos diferentes grupos de observação.

\section{CONCLUSÕES}

A aplicação tópica do plasma rico em plaquetas de equino associada com a pomada contendo gentamicina, sulfanilamida, sulfadiazina, ureia e vitamina $\mathrm{A}$, em feridas de pele em coelhos, é eficaz na maturação mais precoce das fibrilas colágenas, antecipando o processo cicatricial. A coloração picrosírius não foi sensível para a avaliação das fibras colágenas nos diferentes grupos, enquanto a microscopia eletrônica de transmissão foi o melhor método de avaliação. A maturação da fibrila colágena é determinada pelo diâmetro e pela densidade da fibrila colágena por área, ou seja, quanto menor o diâmetro da fibrila, maior será sua densidade por área e maior o seu grau de maturação.

\section{REFERÊNCIAS}

ABEGÃO, K.G.B.; BRACALE, B.N.; DELFIN, I.G. et al. Effects of heterologous platelet-rich plasma gel on standardized dermal wound healing in rabbits. Acta Cir. Bras., v.30, p.209$215,2015$.

ALEIXO, G.A.; ZACARIAS, T.F.; MAIA, F.C. et al. Comparação entre dois protocolos para obtenção de plasma rico em plaquetas, em cães. Arq. Bras. Med. Vet. Zootec., v.63, p.567-573, 2011.

ANDRADE, M.; RODRIGUES, G.M.; LIMA, D.P. et al. Use of plasma rich in platelets of rabbits with few leukocytes and erythrocytes to consolidate bones. Arq. Bras. Med. Vet. Zootec., v.68, p.276-282, 2016.

ARORA, S.; DODA, V.; KOTWAL, U.; DOGRA, M. Quantification of platelets and platelet derived growth factors from plateletrich-plasma (PRP) prepared at different centrifugal force (g) and time. Transfus. Apher. Sci., v.54, p.103-110, 2016.

BIRK, D.E.; FITCH J.M.; BABIARZ, J.P. et al. Collagen fibrillogenesis in vitro: interaction of types I and V collagen regulates fibril diameter. J. Cell. Sci., v.95, p.649-657, 1990.

BOZZOLA, J.J.; RUSSELL, L.D. Electron microscopy: principles and techniques for biologists. (TheJones and Bartlett series in biology). 2.ed. Boston: Jones and Bartlett, 2006. 542p.

CAMPOS, A.C.L.; BORGES-BRANCO, A.; GROTH, A.K. Cicatrização de feridas. Arq. Bras. Cir. Dig., v.20, p.51-58, 2007.

CHANG, P.; GUO, B.; HUI, Q. et al. A bioartificial dermal regeneration template promotes skin cell proliferation in vitro and enhances large skin wound healing in vivo. Oncotarget, v.8, p.25226-25241, 2017.

EURIDES, D.; MANTOVANI, M.M.; MENEZES, G.F. et al. Plasma rico em plaquetas autólogas na cicatrização do tendão do músculo gastrocnêmio de coelhos. Braz. J. Vet. Res. Anim. Sci., v.52, p.48-56, 2015.

HERMETO, L.C.; ROSSI, R.; PÁDUA, S.B. et al. Comparative study between fibrin glue and platelet rich plasma in dogs skin grafts. Acta Cir. Bras., v.27, p.789-794, 2012. 
HOUDEK, M.T.; WYLES, C.C.; STALBOERGER, P.G. et al. Collagen and fractionated platelet-rich plasma scaffold for dermal regeneration. Plast. Reconstr. Surg., v.137, p.1498-1506, 2016.

HUANG, L.; APKARIAN, R.P.; CHAIKOF, E.L. High-resolution analysis of engineered type I collagen nanofibers by electron microscopy. Scanning, v.23, p.372-375, 2001.

MA, X.; BAZAN, H.E. Increased plateletactivating factor receptor gene expression by corneal epithelial wound healing. Invest. Ophthalmol. Vis. Sci., v.41, p.1696-1702, 2000.

MASI, E.C.D.J.; CAMPOS, A.C.L.; MAIS, F.D.J. et al. The influence of growth factors on skin wound healing in rats. Braz. J. Otorh., v.82, p.512-521, 2016.

MINAMIMURA, A.; ICHIOKA, S.; SANO, H.; SEKIYA, N. Comparison of collagen matrix treatment impregnated with platelet rich plasma vs bone marrow. J. Plast. Surg. Hand Surg., v.48, p.15-20, 2014.
MORI, R.; TANAKA, K.; DE KERCKHOVE, M. et al. Reduced FOXO1 expression accelerates skin wound healing and attenuates scarring. Am. J. Pathol., v.184, p.2465-2479, 2014.

SOUSA, S.M.T.; SILVA, C.B.; SILVA, N.J. et al. Potencial de cicatrização do látex de synadenium umbellatum em feridas dorsais de ratos. Estudos, v.42, p.481-491, 2015.

SOUZA, M.V.; PINTO, J.O; COSTA, M. et al. Quantificação de fatores de crescimento na pele de equinos tratada com plasma rico em plaquetas. Pesqui. Vet. Bras., v.34, p.599-612, 2014.

STARBORG, T.; KALSON, N.S.; LU, Y. et al. Using transmission electron microscopy and 3 View to determine collagen fibril size and three-dimensional organization. Nat. Protoc., v.8, p.1433, 2013.

TONNIGES, J.R.; ALBERT, B.; CALOMENI, E.P. et al. Collagen fibril ultrastructure in mice lacking discoidin domain receptor 1. Microsc. Microanal., v.22, p.599-611, 2016. 